\title{
Editorial
}

\section{Tax illusion and the scope for cutting tax rates}

Barry Bracewell-Milnes, Banstead, United Kingdom

It is widely believed in Britain that, over the ten years since it come to power, the present British Government has reduced taxation substantially, even imprudently. The truth is the opposite. Not only has tax revenue risen in nominal terms (before adjustment for inflation) and also in 'real' terms (after adjustment for inflation); it has even risen as a proportion of gross domestic product (which is much the most usual definition of the tax burden). Tax revenue rose from 32.9 per cent of GDP in 1979 to an estimated 37.5 per cent in 1989-90, a rise of nearly five percentage points. The reasons for this sharp contrast between perception and reality have implications for tax policy both in Britain and elsewhere.

The structure of the British tax system is such that tax revenue is inherently buoyant or 'income-elastic': as the tax bases rises (with or without adjustment for inflation), tax revenue rises faster. There are four main reasons for this: first, the schedule of income tax rates is regularly adjusted for inflation but not for the growth of real earnings; second, the structure of corporation tax rates is not adjusted even for inflation; third, the corporation tax base makes no allowance for inflationary gains in the value of stocks or inflationary reductions in the value of depreciation allowances; fourth, value added tax is levied on 'luxuries' rather than 'necessaries', so that revenue from value added tax rises more rapidly than income. These and other influences have outweighed the effects of reduction in tax rates: the large reductions in income tax rates, in particular, have done no more than prevent the tax burden from rising by more than five percentage points.

Two of these four influences are sensitive to the rate of inflation and two to 'real' economic growth. These and other influences would disappear only for as long as inflation and economic growth were both zero. In practice, therefore, they are likely to remain important for the foreseeable future. The revenue will continue to benefit from disproportionalities in the tax system ('fiscal drag') and the public will continue to believe that tax reductions have reduced the tax burden even if the burden has risen ('tax illusion'). The amounts involved are substantial. Fiscal drag was estimated by Chancellor Lawson at some $£ 6$ billion in a full year in March 1988 and at some $£ 3$ billion in a full year in March 1989; in a normal year (which 1990 may not be) these figures may represent the upper and lower limits of fiscal drag. The full-year yield of 1 penny on the basic rate of income tax is currently some $£ 2$ billion.

The policy implication for Britain is that in normal years there will for the foreseeable future be scope for significant reductions in tax rates even if the tax burden remains. unchanged (that is, even if tax revenue rises in line with money GDP). Reductions in tax rates are necessary to prevent the tax burden from rising; and even large reductions in tax rates may be inadequate for this purpose. A steady and continuing reduction in tax rates is thus compatible with the maintenance of tax revenue (and government spending) not merely at their present levels but at their present shares of GDP.

The argument and the policy implication would appear to hold good for other western industrialised countries as well as Britain. 